\title{
Evaluation of Toric IOL Implantation in Different Degrees of Astigmatism
}

Essam El Din Shoheib, Ashraf El Shayeb, Walid Abelghaffar, Mohamed Moustafa Baz

Department of ophthalmology,

Benha faculty of medicine, Banha University, Egypt.

Correspondence to:

Mohamed Moustafa Baz, Department of ophthalmology, Benha faculty of medicine, Banha University, Egypt.

Email:

dr_mohamedbaz@yahoo.com

Received: 15 October 2019

Accepted: 17 May 2021

\begin{abstract}
Background: correction of the pre-existing regular corneal astigmatism during phacoemulsification. Purpose: Evaluation of the toric IOL rotational stability and efficacy in patients with cataract with pre-existing astigmatism. Patients and methods: 30 eyes of 30 patient of age ranged from 45-75 years old had phacoemulsification surgery with pre-existing regular astigmatism ranged from 1.5-4.5 D without any corneal of ocular abnormality. The patients were examined one week, one month, and third month postoperative. The stability and efficacy were evaluated by the slit lamp against a dilated pupil and by the auto refractometer to measure the postoperative refraction.Results: The IOL axis of orientation is evaluated against the red reflex and calculation of any rotation No need to readjust the IOLs were made. A stable refraction is obtained by the first month with no changes in the follow up period. Conclusion: The toric IOL was much stable,
\end{abstract} effective and predictable way in correction of astigmatism.

Keywords: Toric IOL, astigmatism, phacoemulsification

\section{Introduction:}

Patients have high expectations for visual rehabilitation after cataract surgery. Standard monofocal intraocular lenses (IOLs) successfully address the spherical component of vision correction; however, approximately $35 \%$ of patients with cataracts have 1.00 diopter (D) or more of corneal astigmatism with $15 \%$ to $20 \%$ having $1.5 \mathrm{D}$ or more of corneal astigmatism. ${ }^{(1)}$

Patients with cataracts and corneal astigmatism may benefit from astigmatism correction with toric IOLs. To achieve optimal visual acuity postoperatively, 
patients with cataracts and corneal astigmatism who receive traditional spherical monofocal IOLs often need spectacles or additional corneal refractive procedures. $^{(2)}$

Astigmatism causes a loss of visual acuity of about 1.5 lines per diopter of uncorrected cylinder, such that even low amounts of uncorrected cylinder can reduce uncorrected visual function. ${ }^{(3)}$.

Toric IOLs have been designed to replace cataractous lenses, reduce postoperative astigmatism, and decrease or eliminate the need for distance vision spectacle use or additional surgery. Toric IOLs may provide greater reversibility or adjustability than some keratorefractive procedures. ${ }^{(4 .)}$

\section{Patients and methods:}

This prospective study were done over 30 eyes of 30 patient of age ranged from $45-75$ years old had phacoemulsification surgery with pre-existing regular astigmatism ranged from 1.5-4.5 D. from multicenter in Egypt during the period from June 2017 till February 2019.

Before the start of this study, the protocol, the patients were informed by a consent form and any other written information to be given to was reviewed and approved by the Ethics Committee of the ministry of health of Egypt.

Each patient was informed about the nature of the study, its purpose, the surgical procedures involved, the follow up duration, the potential risks, benefits involved and any discomfort that may be caused.

\section{- Exclusion Criteria:}

○ Corneal opacities, previous corneal surgery.

○ Irregular astigmatism.

o Concurrent posterior segment disease.

○ Glaucoma.

○ Occurrence of intraoperative complication e.g. vitreous loss.

For each patient pre-operative data was collected including patient demographics; sex, age, and telephone number.

\section{All patients were subjected to the following:}

○ Complete medical assessment.

○ complete general ophthalmic examination was be done in all patients including : 
Uncorrected visual acuity (UCVA).

Auto refractometer readings, (Retinoscopy was done when cataract makes auto refractometer reading difficult).

Best spectacle-corrected visual acuity (BCVA).

Keratometry.
Slit lamp biomicroscope, retinal evaluation, Iop measurment by using Goldman applanation tonometer.

\section{- Planning surgery:}

The data collected from the preoperative assessment were used in planning the surgical procedure. For the toric IOL implantation we used the online toric IOL calculator (Figure 1).

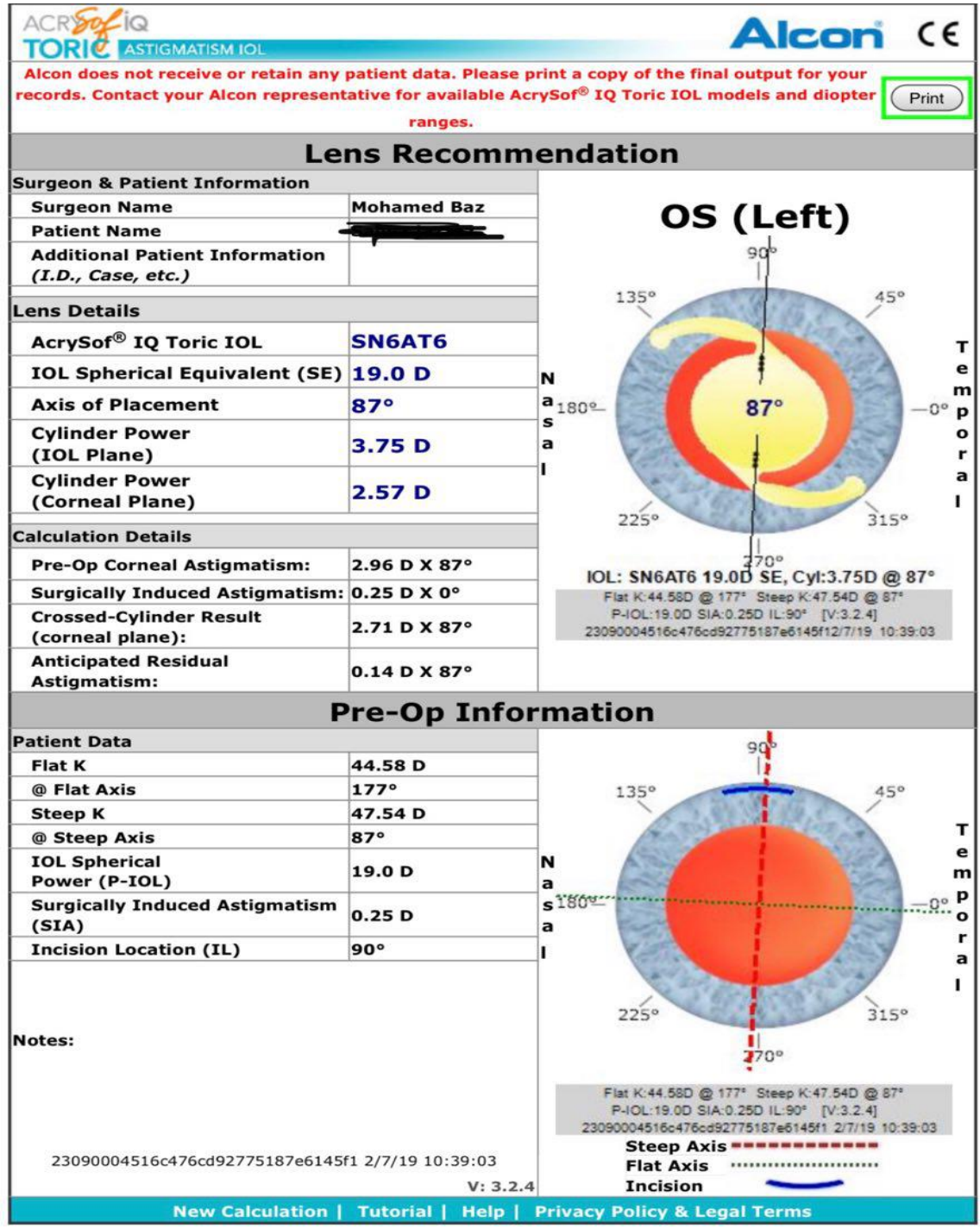

Figure (1) online toric IOL calculation 
For the toric online calculator, the surgeon name, patient data, which eye (right or left), the $\mathrm{K}$ readings with the axes, the spherical equivalent from IOL master, the site of the main incision and the surgically induced astigmatism by the surgeon were filled. The print out provides us with the model, power of the IOL and the axis of implantation.

\section{- On the day of the operation}

For hour and half preoperatively, the pupil of the marked eye was dilated by using topical application of a combination of tropicamide $1 \%$, phenylephrine hydrochloride $2.5 \%$ and Flurbiprofen 0.03 $\%$.

Before starting the surgery, a marker was used to put an orientation mark at the 3 and 9 O'clock position correlated to the 180 axis at the limbus while the patient is sitting. This is an important step to avoid head tilting or cyclotorsion that may occur following lying flat or after injection of anesthesia. (Figure 2).

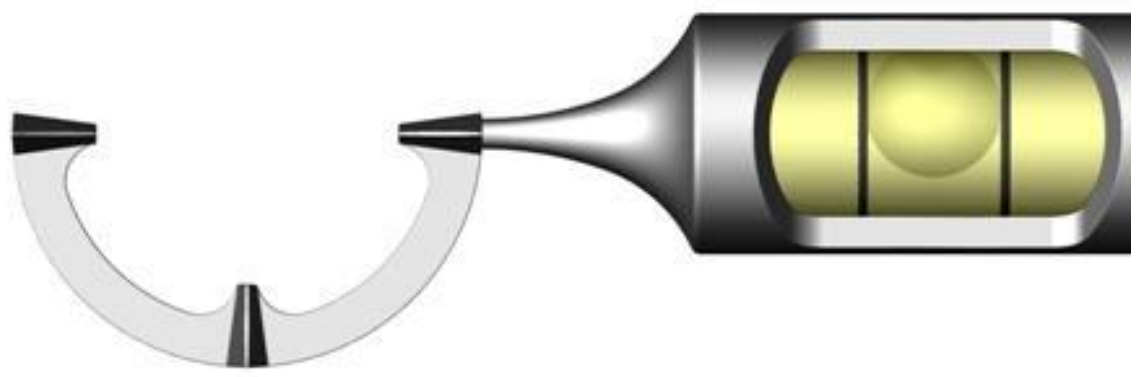

Figure (2): Reference marker for the horizontal meridian.

The cases were done with local (peribulbar) anesthesia by using a mixture of lidocaine hydrochloride $20 \mathrm{mg} / \mathrm{ml}$ (xylocaine $2 \%$ ) and hyaluronidase $1.500 \quad$ IU/ampule (Hyalase).

\section{- Surgical steps:}

o First step is disinfection by povidone iodine and draping, the operation starts by applying a wire speculum.
○ The steep corneal meridian as indicated by the IOL Master was identified and marked at the start of surgery, using a marking pen.(together with the preoperative marking this is called 3 step marking technique)

$\circ$ Two side port paracentesis were done at about $90^{\circ}$ or 4 clock hours on either side of the main incision using a MVR 19 gauge. 
o Sodium hyaluronate $1.35 \%$ (Healon) was injected through one of the side ports to fully inflate the anterior chamber.

○ A clear corneal tunnel incision was done by an angled $2.2 \mathrm{~mm}$ keratome. The entry site into the cornea was just in front of the limbal capillaries .The incision was completed into a tunnel of $2.0 \mathrm{~mm}$ in length.

○ A continuous curvilinear capsulorhexis was performed using a cystotome or capsulorhexis forceps. Hydrodissection was done using a 27 gauge flattened tip cannula, followed by rotation of the nucleus.

○ We used infinity phaco machine to perform phacoemulsification in the posterior chamber with a divide and conquer or stop and chop technique in all cases- After phacoemulsification of the nucleus, the cortex was removed by automated I/A. Then the bag and the anterior chamber were inflated by the same viscoelastic material.

○ Then, marking the axis of implantation using a Mendeez ring according to the toric IOL calculator.

- Implantation of IOL using a lens injector and $\mathrm{D}$ shaped cartiridge. $\circ$ Rotation of the IOL to the planned orientation. Proper clearance of the viscoelastic from the anterior chamber and behind the IOL which is an important step for implanting a Toric IOL to minimize the risk of the IOL rotation was done followed by stromal hydration of the wound. No sutures were taken in any case.

\section{- The postoperative medication was} as follows:

o Topical prednisolone acetate $1 \%$ eye drops 5 times daily for 1 week then tapered to 4 times / day for the next 2nd week then 3 times / day for the next 3rd week and then twice daily for the $4^{\text {th }}$ week.

O Topical ofloxacin $0.3 \%$ eye drops 5 times daily for 1 week.

All the patients were examined on the slit lamp for follow up first 24 hours, 1 week, 1 month, 3 months after surgery during which UCVA, BCVA, Refraction and dilated slit lamp exam was done to determine if IOL had got any rotation.

\section{Analysis of data was performed as follow:}

The collected data were computerized and statistically analyzed using SPSS program 
(Statistical Package for Social Science) version 24 .

- Data were tested for normal distribution using the Shapiro Walk test.

- Qualitative data were represented as frequencies and relative percentages.

- Quantitative data were expressed as median and range for being non-parametric data (not normally distributed).

- Wilcoxon Signed Ranks test to compare the changes before and after follow up for nonparametric variables.
- All statistical comparisons were two tailed with significance Level of P-value $\leq 0.05$ indicates significant, $\mathrm{P}<0.001$ indicated highly significant difference while, $\mathrm{p}>$ 0.05 indicates Non-Significant difference.

\section{Results:}

This part of the study included 30 eyes of 30 patients 12 of which were females and 18 patients were males (Table 2) (fig 3) mean age of 58.2 \pm 5.4 years old (range 52-68 years old) (table 1). Number of the right eyes (OD) was 6 eyes of percentage $20 \%$ and number of the left eyes (OS) was 24 eyes of percentage 80\%. Table (3) Fig (20).

Table (1): Age of patients at the time of the study

\begin{tabular}{lll}
\hline & & Value \\
\hline Age (yrs) & Median (Range) & $57(52-68)$ \\
& Mean \pm SD & $58.2 \pm 5.4$ \\
\hline
\end{tabular}

Table (2): Sex distribution in the studied population $(\mathrm{N}=30)$

\begin{tabular}{lcc}
\hline & No. & Percent \\
\hline Female & 12 & $40.0 \%$ \\
Male & 18 & $60.0 \%$ \\
\hline
\end{tabular}

Table (3): frequency of examined eye in the studied population $(\mathrm{N}=30)$

\begin{tabular}{lll}
\hline & No. & Percent \\
\hline OD & 6 & $20.0 \%$ \\
OS & 24 & $80.0 \%$ \\
\hline
\end{tabular}




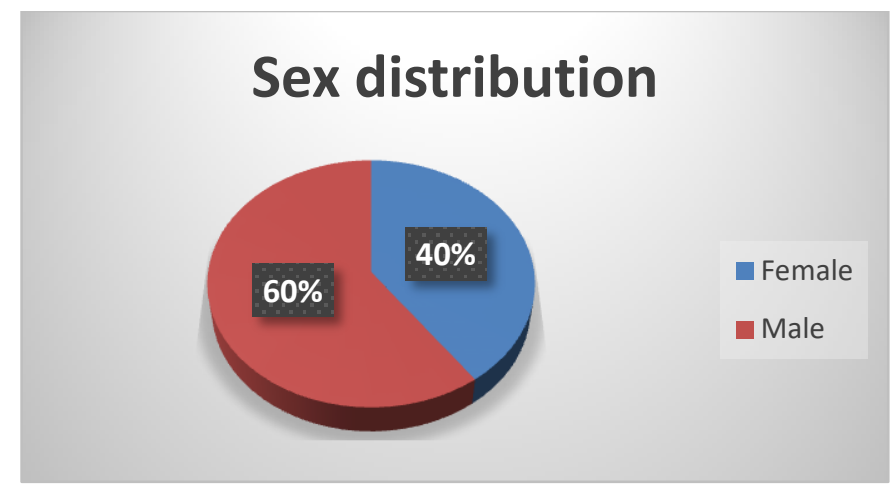

Fig (3): Sex distribution in the studied group $(\mathbf{N}=\mathbf{3 0})$

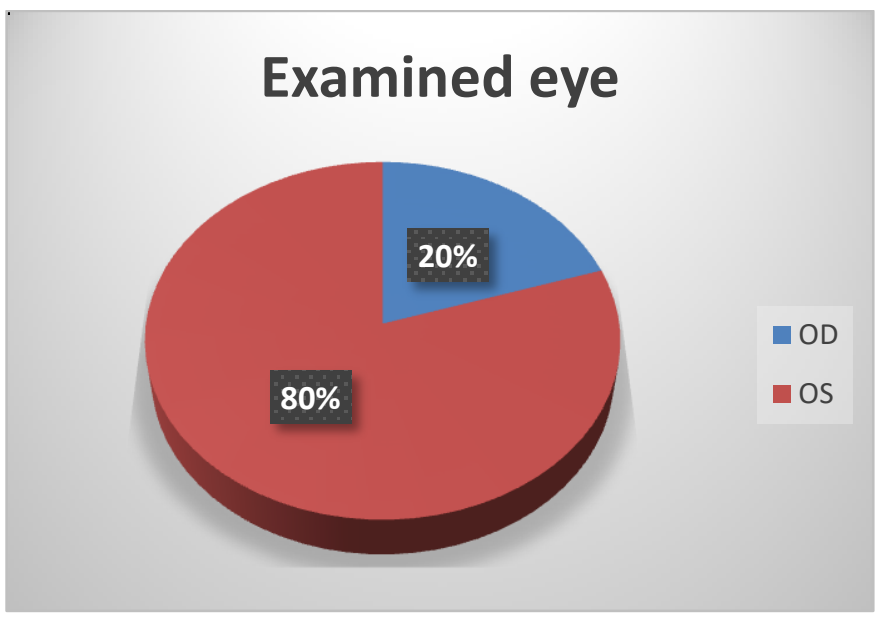

Fig (4): frequency of examined eye in the studied population $(\mathrm{N}=30)$

The preoperative corneal astigmatism less than 3.00 diopters with $60 \%$ of cases (18 eyes), while those having astigmatism more than 3.00 diopters were $40 \%$ of cases (12 eyes).

Dilated examination for each case in the first day to find out if there is any significant rotation for the IOL was done. Neither of the cases needs re-entry to the operating room to readjust the position of the IOL. The mean error in placement was less than 2 degrees.

Using the unpaired test, the UCVA at first week was examined the following results are recorded with decimal notation for the visual acuity was used. Table (4): 
Table (4): Comparison between the visual outcomes (UCVA) Pre-operative and $1 \mathrm{~W}$ post-operative

\begin{tabular}{lllll}
\hline UCVA & Pre-operative & $1 \mathrm{w}$ post-operative & Wilcoxon Test & $\mathrm{P}$ \\
Median (Range) & $0.1(0.1-0.2)$ & $0.7(0.5-0.8)$ & -4.8 & $<\mathbf{0 . 0 0 1}$ \\
\hline
\end{tabular}

Using the unpaired test, the UCVA at first month was examined the following results are recorded with decimal notation for the visual acuity was used. Table (5):

Table (5): Comparison between the visual outcomes (UCVA) Pre-operative and 1M post-operative

\begin{tabular}{lllll}
\hline UCVA & Pre-operative & 1 M post-operative & Wilcoxon Test & P \\
Median (Range) & $0.1(0.1-0.2)$ & $0.7(0.5-0.8)$ & -4.8 & $<\mathbf{0 . 0 0 1}$ \\
\hline
\end{tabular}

Using the unpaired test, the UCVA at third month was examined the following results are recorded with decimal notation for the visual acuity was used. Table (6):

Table (6): Comparison between the visual outcomes (UCVA) Pre-operative and 3 M post-operative

\begin{tabular}{lllll}
\hline UCVA & Pre-operative & 3 M post-operative & Wilcoxon Test & $\boldsymbol{P}$ \\
Median (Range) & $0.1(0.1-0.2)$ & $0.7(0.5-0.8)$ & -4.8 & $<\mathbf{0 . 0 0 1}$ \\
\hline
\end{tabular}

The following figure shows the follow up of the UCVA for the first three months figure (5).

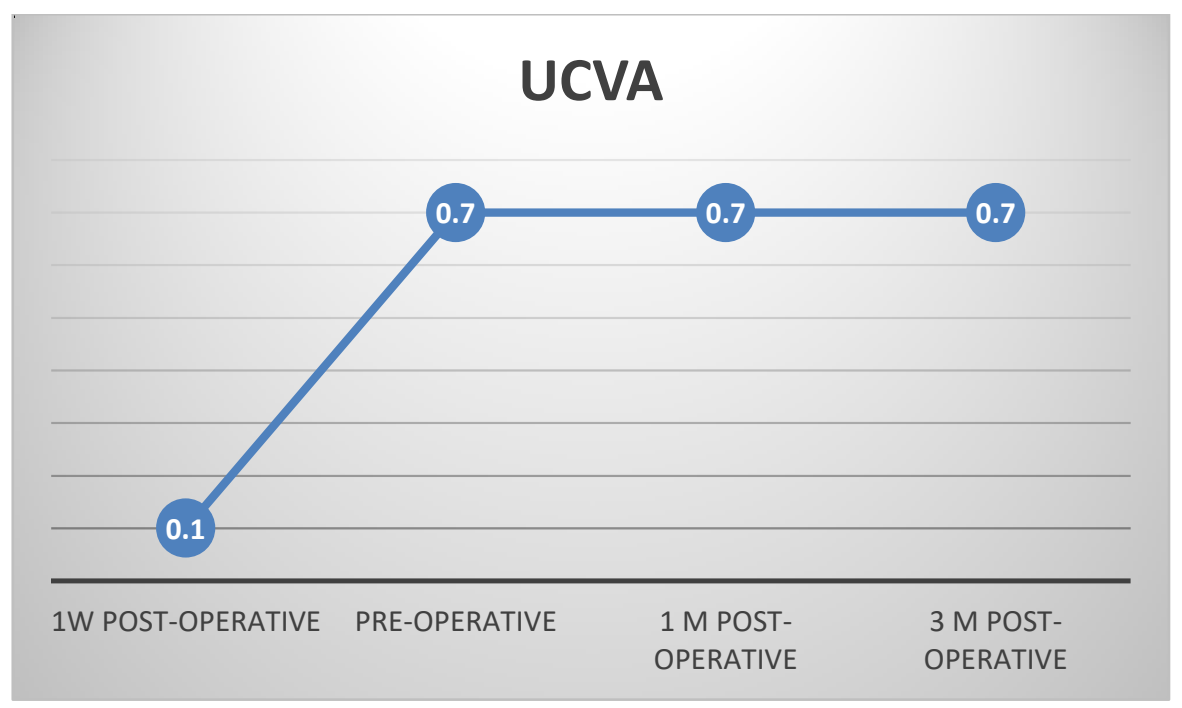

Fig (5): the visual outcomes (UCVA) Pre-and Post-operative measures

Using the unpaired test, the BCVA at first week was examined and the following results are recorded with decimal notation for the visual acuity was used. Table (7) 
Table (7): Comparison between the visual outcomes (BCVA) Pre-operative and 1W post-operative:

\begin{tabular}{lllll}
\hline BCVA & Pre-operative & 1w post-operative & Wilcoxon Test & $P$ \\
Median (Range) & $0.2(0.1-0.3)$ & $0.8(0.6-0.9)$ & -4.8 & $<\mathbf{0 . 0 0 1}$ \\
\hline
\end{tabular}

There was an improvement of the BCVA in the first week with range of 0.8 and $p$ value $<0.001$

Using the unpaired test, the BCVA at first month was examined the following results are recorded with decimal notation for the visual acuity was used. Table (8)

Table (8): Comparison between the visual outcomes (BCVA) Pre-operative and 1M post-operative:

\begin{tabular}{lllll}
\hline BCVA & Pre-operative & 1 M post-operative & Wilcoxon Test & $P$ \\
Median (Range) & $0.2(0.1-0.3)$ & $0.8(0.6-0.9)$ & -4.8 & $<0.001$ \\
\hline
\end{tabular}

Using the unpaired test, the BCVA at third month was examined the following results are recorded with decimal notation for the visual acuity was used. Table (9)

Table (9): Comparison between the visual outcomes (BCVA) Pre-operative and 3 M post-operative:

\begin{tabular}{lllll}
\hline BCVA & Pre-operative & 3 M post-operative & Wilcoxon Test & $\boldsymbol{P}$ \\
Median (Range) & $0.2(0.1-0.3)$ & $0.8(0.6-0.9)$ & -4.8 & $<\mathbf{0 . 0 0 1}$ \\
\hline
\end{tabular}

The following figure shows the follow up of the BCVA for the first three months figure (6).

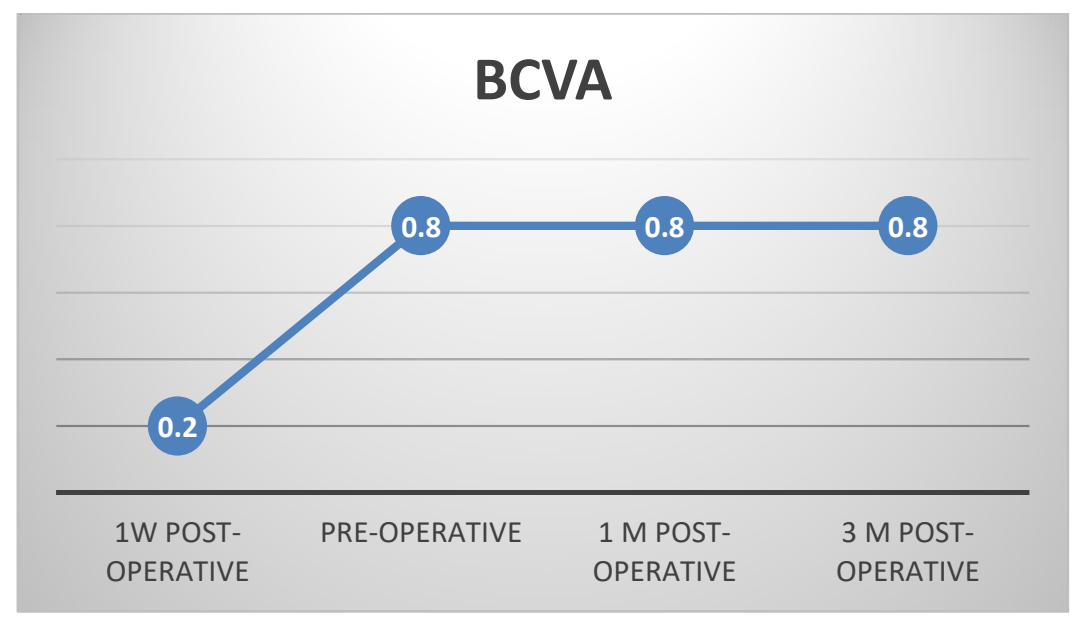

Fig (6): the visual outcomes (BCVA) Pre-and Post-operative measures

\section{IOL rotation}

For each visit in the follow up during this study dilated examination with slit lamp photography was performed after remarking the axis of astigmatism. The IOL axis of orientation is evaluated against the red reflex and calculation of any rotation No need to readjust the IOLs were made. 


\section{Discussion:}

There are several procedures for reducing preexisting regular astigmatism during cataract surgery.

In this study we use implantation of toric IOLs during phacoemulsification as one of procedures for the correction of preexisting regular astigmatism.

It was reported (2) that any patient with astigmatism more than $1.50 \mathrm{D}$ is considered a candidate for some form of surgical astigmatic correction $^{(2)}$

So, our inclusion criteria required that total cylinder should be 1.5 to $4.50 \mathrm{D}$ before surgery.

Our surgical procedure for reduction of preexisting regular astigmatism during cataract surgery we evaluated in our study is implantation of toric IOL.

In our study we have cases with cataract and regular astigmatism. This was similar to Holland and co-workers who carried out a randomized, multicenter study that included 517 eyes (Toric IOL, n=256; control IOL, $\mathrm{n}=261$ ). They concluded that better efficacy, rotational stability, distance vision spectacle freedom, and safety results support the use of the AcrySof ${ }^{\circledR}$ Toric IOL (Alcon
Laboratories, FW, Tx) for patients with cataracts and regular corneal astigmatism. ${ }^{(5)}$

We used 2.2 alcon keratome for the clear corneal incision. The difference between using 2.2-mm incision micro-coaxial phacoemulsification and traditional $3.0-\mathrm{mm}$ coaxial phacoemulsification with respect to surgically induced astigmatism (SIA) in temporally clear corneal incision for cataract surgery, was evaluated ${ }^{(6)}$. The researchers found that there is significant reduction for surgically induced astigmatism with the smaller incision size $(2.2 \mathrm{~mm}) .{ }^{(6)}$

We used intraoperative Mendez ring with the preoperative reference markings to determine the axis of IOL implantation that aligned according to these marks without usage of any other special techniques. Using iris finger printing technique, was described where a pre-operative detailed image of the eye is obtained, in which the alignment axis is drawn. The printout of this image is used to align the toric IOL during surgery based on iris characteristics. ${ }^{(7)}$

A study was done with Atsushi and coworkers in 2016 including 18 eyes of 16 patients underwent cataract surgery with a toric IOL implantation (AcrySof IQ Toric), showed that the mean postoperative 
remaining refractive astigmatism of $0.73 \pm 0.55$ diopters (D). ${ }^{(8)}$

A study demonstrated that there was no need for secondary surgery for IOL repositioning. Our study results are similar to those reported by, this prospective randomized controlled study, included 42 eyes of 42 cataractous patients with preexisting regular corneal astigmatism of $1 \mathrm{D}$ or more were randomized to receive plate haptic toric (ATTORBI) or loop haptic toric (AcrySof) IOLs, with 21 in each group, The mean IOL rotation at 3 months follow-up in plate haptic group was found to be $3.52 \pm 3.84^{\circ}$ and in loop haptic group was $2.05 \pm 2.56^{\circ}$ (P $=0.25^{\text {). (9) }}$

The early rotational stability of AcrySof SN60T toric IOLs was compared with that in a retrospective series of AA4203 toric IOLs. In the AcrySof SN60T group, 90\%, $99 \%$ and $100 \%$ of the IOLs were aligned at or within 5, 10 and 15 degrees, respectively, of the planned axis and the same was seen in the AA4203 group in 70\%, $90 \%$ and $97 \%$, respectively. The mean IOL rotation was $5.56 \pm 8.49$ degrees in the AA4203 group and $3.35 \pm 3.41$ degrees in the AcrySof SN60T group $(\mathrm{p}=.0232)$. They concluded that based on the mean axis deviation and the number of IOLs rotating $5^{\circ}$ or more, the
AcrySof SN60T toric IOL gives out statistically better rotational stability ${ }^{(10)}$

Many causes may lead to unwanted postoperative IOL rotation. Incomplete removal of viscoelastic and early postoperative IOP (intraocular pressure) fluctuation both result in rotational instability. When fusion between anterior and posterior capsules occured, IOL rotation rate decreases. ${ }^{(11)}$

\section{References:}

1. Ferrer-Blasco T, Montés-Micó R, Peixotode-Matos SC, González-Méijome JM, Cerviño A. Prevalence of corneal astigmatism before cataract surgery. Journal of Cataract \& Refractive Surgery. 2009 Jan $1 ; 35(1): 70-5$.

2. Budak K, Friedman NJ, Koch DD. Limbal relaxing incisions with cataract surgery. Journal of Cataract \& Refractive Surgery. 1998 Apr 1;24(4):503-8.

3. Atchison DA, Guo H, Charman WN, Fisher SW. Blur limits for defocus, astigmatism and trefoil. Vision Research. 2009 Sep 30;49(19):2393-403.

4. Titiyal JS, Agarwal T, Jhanji V. Toric intraocular lens versus opposite clear corneal incisions to correct astigmatism in eyes having cataract surgery. Journal of cataract \& refractive surgery. 2009 Oct 1;35(10):1834-5. 
5. Holland E, Lane S, Horn JD, Ernest P, Arleo R, Miller KM. The AcrySof Toric intraocular lens in subjects with cataracts and corneal astigmatism: a randomized, subject-masked, parallel-group, 1-year study. Ophthalmology. $2010 \quad$ Nov 1;117(11):2104-11.

6. Masket S, Wang L, Belani S. Induced astigmatism with 2.2 -and $3.0-\mathrm{mm}$ coaxial phacoemulsification incisions. Journal of Refractive Surgery. 2009 Jan 1;25(1):21-4.

7. Visser N, Bauer NJ, Nuijts RM. Toric intraocular lenses: historical overview, patient selection, IOL calculation, surgical techniques, clinical outcomes, and complications. Journal of Cataract \& Refractive Surgery. 2013 Apr 1;39(4):62437.

8. Kawahara A, Takayanagi Y. Vector analysis investigation of toric intraocular lens with no deviation from the intended axis. Clinical ophthalmology (Auckland, NZ). 2016;10:2199.

9. Seth SA, Bansal RK, Ichhpujani P, Seth NG. Comparative evaluation of two toric intraocular lenses for correcting astigmatism in patients undergoing phacoemulsification. Indian journal of ophthalmology. 2018 Oct;66(10):1423.

10. Chang DF. Comparative rotational stability of single-piece open-loop acrylic and platehaptic silicone toric intraocular lenses. Journal of Cataract \& Refractive Surgery. 2008 Nov 1;34(11):1842-7.

11. Packer M, Williams JI, Feinerman G, Hope RS. Prospective multicenter clinical trial to evaluate the safety and effectiveness of a new glistening-free one-piece acrylic toric intraocular lens. Clinical ophthalmology (Auckland, NZ). 2018;12:1031.

To cite this article: Essam El Din Shoheib, Ashraf El Shayeb, Walid Abelghaffar, Mohamed Moustafa Baz Evaluation of Toric IOL Implantation in Different Degrees of Astigmatism. BMFJ 2022;39 (ophthalmology):12-23. DOI: 10.21608/bmfj.2021.18242.1101 